National Center for Family \& Marriage Research

@ Bowling Green State University

Family Profile No. 13, 2021

\title{
Median Age at First Marriage: Geographic Variation, 2019
}

Author: Krista K. Payne

In this profile, the median age at first marriage is estimated for the nation and each state by gender among those aged 15-54 for 2019, using 1-year estimates from the American Community Survey (ACS) (Table B12007). Direct estimates of the age at which half of men and women (who in the last year) married for the first time as well as the associated margins of error are provided.

The ACS has been collecting data on marriage for over a decade.

Trend in Median Age at First Marriage by Gender, 2008-2019

- The U.S. median age at first marriage is at a historic highpoint (FP-21-12).

- Since 2008 , the age at first marriage has increased by 2.3 years surpassing 30 years of age among men. Among women it has increased by 2.2 years to over 28 years of age (Figure 1).

Figure 1. Men and Women's Median Age at First Marriage, 2008 \& 2019

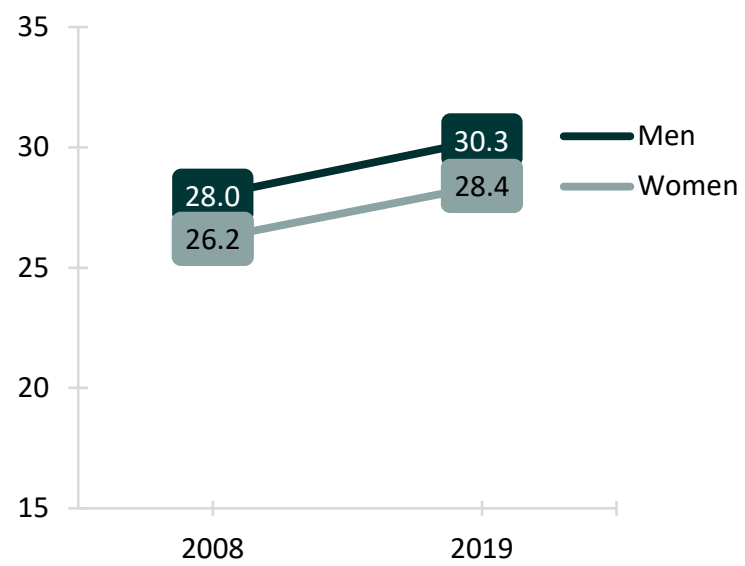

Source: U.S. Census Bureau, American Community Survey, 1-year est., Table B12007, 2008 \& 2019

Note: Universe is men and women between the ages of 15 and 54

States with the Highest and Lowest Median Age at First Marriage by Gender, 2019

- Men living in Connecticut had the highest median age at first marriage at 32.1 years. Conversely, men in Wyoming had the youngest median age at first marriage of 26.5.

- Women who lived in Rhode Island experienced the highest median age at first marriage (30.5), while women living in Utah had the lowest at 24.8.

Table 1. Median Age at First Marriage, 2019: Men's Top \& Bottom Five States

\begin{tabular}{|clcc|}
\hline Rank & State & Age & MOE \\
\hline 1 & Connecticut & 32.1 & $+/-0.6$ \\
2 & Vermont & 31.9 & $+/-1.3$ \\
2 & Rhode Island & 31.8 & $+/-1.1$ \\
4 & New York & 31.5 & $+/-0.2$ \\
5 & Florida & 31.5 & $+/-0.4$ \\
\hline & U.S. & 28.4 & $+/-0.1$ \\
47 & Idaho & 27.9 & $+/-1.1$ \\
48 & Oklahoma & 27.6 & $+/-0.6$ \\
48 & Arkansas & 27.0 & $+/-0.7$ \\
50 & Utah & 26.7 & $+/-0.5$ \\
51 & Wyoming & 26.5 & $+/-1.2$ \\
\hline
\end{tabular}

- Three states are ranked at the top for oldest ages at first marriage among both men and women Connecticut, New York, and Rhode Island.

- Four states ranked at the bottom with the youngest ages at first marriage for both men and womenArkansas, Idaho, Utah, and Wyoming.

Table 2. Median Age at First Marriage, 2019: Women's Top \& Bottom Five States

\begin{tabular}{|clcc|}
\hline Rank & State & Age & MOE \\
\hline 1 & Rhode Island & 30.5 & $+/-0.9$ \\
2 & Massachusetts & 30.1 & $+/-0.9$ \\
2 & Wash, D.C. & 30.1 & $+/-0.2$ \\
4 & Connecticut & 30.0 & $+/-0.4$ \\
5 & New York & 29.9 & $+/-0.2$ \\
\hline & U.S. & 28.4 & $+/-0.2$ \\
47 & Arkansas & 25.8 & $+/-0.3$ \\
48 & South Dakota & 25.5 & $+/-0.6$ \\
48 & Idaho & 25.5 & $+/-0.4$ \\
50 & Wyoming & 25.4 & $+/-0.8$ \\
51 & Utah & 24.8 & $+/-0.4$ \\
\hline
\end{tabular}


State Rankings and Geographic Variation in the Median Age at First Marriage by Gender, 2019

The state rankings are divided into quartiles with error bars representing the margins of error (MOE). The MOEs for published ACS estimates are provided at a $90 \%$ confidence level.

- Among both men and women, the states in the top quartile were significantly above the national median. The top quartile consisted of ages 31.0 years and older for men and 29.0 years and older women.

- The states falling in the bottom quartile had median ages at first marriage of 28.6 years or younger for men and 26.8 years or younger among women. The median age at marriage the states in the bottom quartile were significantly below the national average.

- Among men and women, most states in the Northeast region had high ages at first marriage-67\% were in the fourth quartile. The exceptions among men included Maine, New Hampshire, and Washington D.C. Among women included Vermont, Maine, and Pennsylvania.

- For men and women, most Midwestern \& Southern states exhibited ages at first marriage in the bottom two quartiles.

- In the West, three states were found in the first quartile among men and women-Idaho, Utah, and Wyoming.

Source: NCFMR analyses of U.S. Census Bureau, American Community Survey, 1-year est., Table B12007, 2019
Figure 2. Men's State-Level Median Age at First Marriage by Quartile, 2019
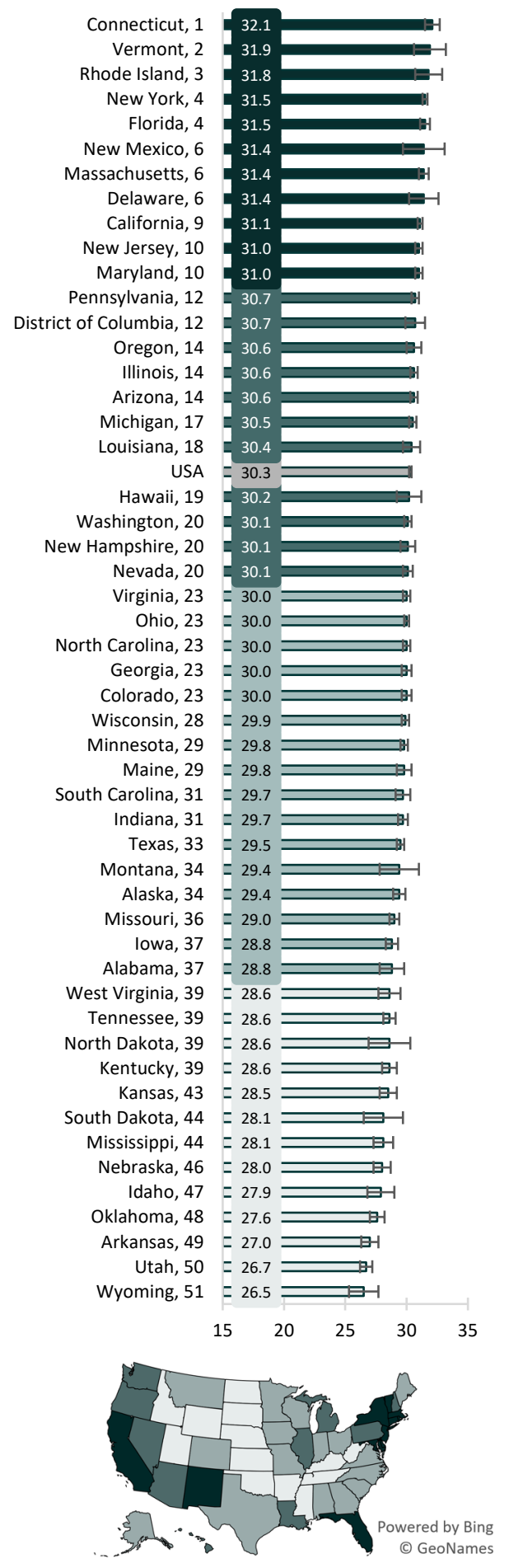

Figure 3. Women's State-Level Median Age at First Marriage by Quartile, 2019

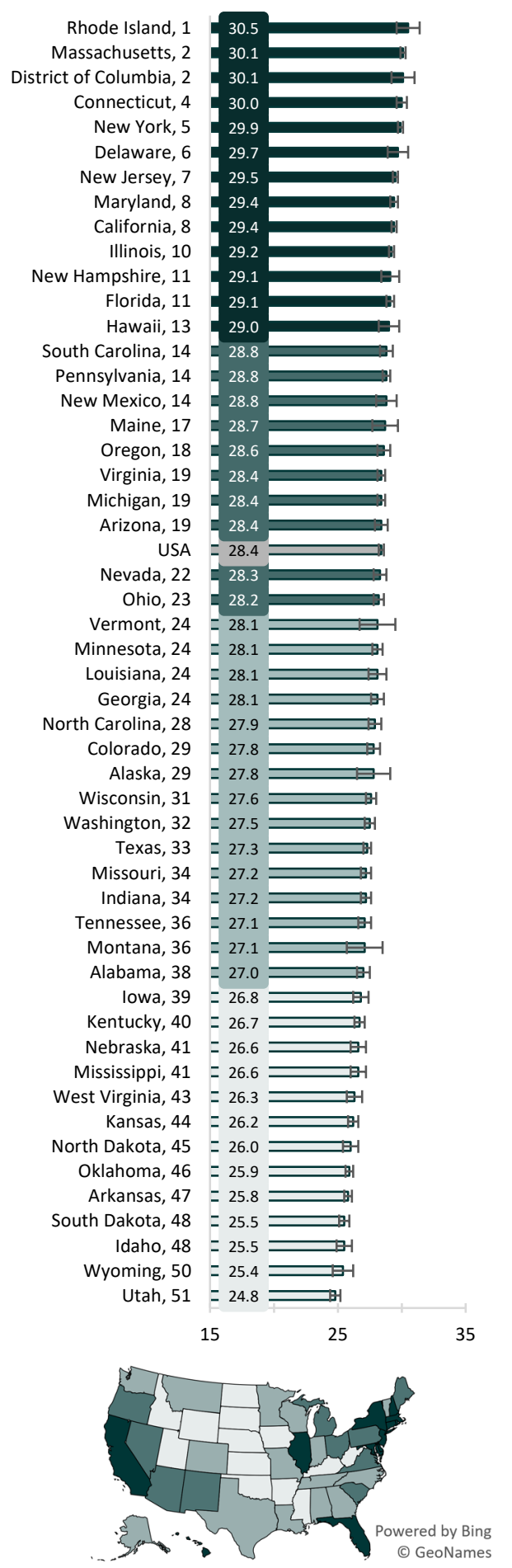

\section{References:}

Payne, K. K. (2021). Median age at first marriage, 2019. Family Profiles, FP-21-12. Bowling Green, OH: National Center for Family \& Marriage Research. https://doi.org/10.25035/ncfmr/fp-21-12

\section{Suggested Citation:}

Payne, K. K. (2021). Median age at first marriage: Geographic variation, 2019. Family Profiles, FP-21-13. Bowling Green, OH: National Center for Family \& Marriage Research. https://doi.org/10.25035/ncfmr/fp-21-13

\section{BCSU. \begin{tabular}{l|l} 
National Center for \\
Family \& Marriage Research
\end{tabular}}

http://www.bgsu.edu/ncfmr ncfmr@bgsu.edu

(419) $372-3119$

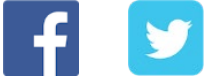

This project is supported with assistance from Bowling Green State University. From 2007 to 2013, support was also provided by the U.S. Department of Health and Human Services, Office of the Assistant Secretary for Planning and Evaluation. The opinions and conclusions expressed herein are solely those of the author(s) and should not be construed as representing the opinions or policy of any agency of the state or federal government. 